\title{
Synthesis of Modern Construction Methods and Local Building Materials: A Drive to Revive Yoruba Vernacular Architecture
}

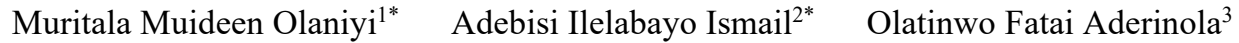 \\ 1.Department of Architectural Technology, Osun state polytechnic, Iree, Osun State, Nigeria \\ 2.Department of Architecture, Ladoke Akintola University of Technology, Ogbomoso, Nigeria \\ 3.Department of Architectural Technology, Federal polytechnic, Offa, Kwara State, Nigeria
}

\begin{abstract}
African vernacular architecture is considered to be one of the notable architecture in the world. This is due to its iconic and cultural representation with very little effort expended on achieving it. The preservation of vernacular buildings has been very difficult across African continents especially in Nigeria. Yoruba vernacular architecture, predominantly in south-western part of Nigeria is in a serious dilapidating state, this is as a result of the drastic shift from the locally sourced building materials to the modern imported ones. Hence, this paper reviews and analyses the causes of the deplorable state of Yoruba vernacular buildings with a view to suggesting appropriate measures to be taken in reviving and preserving them.However, some locally sourced building materials which are adjudged to be economical and sustainable are identified and possible ways of synthesizing them with modern construction methods as a process deemed capable of redeeming the Yoruba vernacular architecture are suggested and discussed.
\end{abstract}

Keywords: African Vernacular Architecture, Yoruba vernacular architecture, Local materials, foreign materials, Indigenous technologies and modern construction methods.

DOI: $10.7176 / \mathrm{JAAS} / 65-04$

Publication date:June $30^{\text {th }} 2020$

\section{Introduction}

The thin line between problems and solutions can be termed as "limitations and challenges". Although, vernacular architecture has been proved by various researchers as a lifetime achievement of the Africans. The move to sustain these vernacular buildings till the end of time requires urgent attention to the various challenges faced with. According to Agboola and Zango (2014), addressing the numerous challenges African Vernacular Architecture is faced with and on time is the only way African architecture can be sustained.

Agboola et al.. (2014) further indicated that the study of vernacular architecture is important for better understanding of the choice of materials and construction methods. This informs today's professionals of the appropriate corrective measures to the problems and challenges vernacular buildings and the built environment as a whole is faced with.

In addition to the use of local materials, Indigenous technology has been of great help for the production of notable edifices in Africa. The zigguratin Egypt which is built of stone and earth around 2640-2621BC is one of the outstanding vernacular buildings in Africa which combines indigenous technology with local materials. In Nigeria context, Centenary hall in Abeokuta, Ogun state is a notable vernacular building which displays an excellent combination of local materials and construction methodology (Adekunle and Odeyale, 2008).

According to Osasona (2005) and Adekunle et al. (2008), local materials such as laterite, wood, thatch, bamboo, snail shell, cow dung, cowries, vines and creepers, Eboto, Ejinrin leaves are readily available building materials in Yoruba land. The use of these materials ensures low cost of traditional building production among the Yoruba folks.

Studies have however shown that there have not been new developments on the construction or building of iconic vernacular buildings in recent times owing to the drastic shift from the use of local building materials and construction techniques to new imported ones and as such the notion of vernacular architecture going into extinction becomes a major issue (Jolaoso\& Bello, 2017).

Obot, (2007),stressed that there is a wide gap between the result that would be obtained when comparing local materials and construction methods with foreign imported ones. The level of civilization among Africans nowadays however has changed the taste of building everybody wants.

Vernacular buildings can be encouraged more in recent times by embracing local materials with a blend of modern construction methods and techniques (Adekunle et al., 2008). It has however been noted that only few literatures have looked into the revival of vernacular architecture among Yoruba folks through a combination of modern construction techniques and local building materials.

This study however, explores ways by which Yoruba vernacular architecture can be preserved through the meaningful combinations of local and foreign materials and technologies to achieving a built environment that will move with time and civilization without losing the rich cultural heritage of the Yorubas and Africa as a whole. 


\section{Culture: a tool for development of Yoruba vernacular Architecture.}

Culture has numerous definitions as explained by different scholars. The description of the built environment of any folk from the concept of culture can be best explained from its social expression. The social expression of culture is very important as it unveils its various components that are considered related to the built environment (Rapoport, 2005).

Cultural components such as kinship, family structure and status have been used by various researchers to explain the concept behind Yoruba vernacular architecture. Extended family practices were very common among the Yoruba folks, even though this has greatly reduced due to civilization. Osasona (2005) indicated that Yoruba people are among the set of people that value coming together to celebrate festive seasons such as Egungun (Masquerade) festivals, Sango festival, Ogun festival, idl-kabir, Christmas and various others. This however requires that spaces which will reflect the identity of people and which will preserve their culture and tradition for their unborn generations be provided.

However, in line with the provision of these spaces, Osasona (2005) noted that status of individuals is an important factor that must be considered as it represents their traditional background, family settings, wealth and affluence. Status as an aspect of culture has been considered as the reason for different house typologies in Yoruba folk architecture. Various Yoruba house typologies are palace, residential buildings, recreational buildings, farm houses among others. It has been noted however from this effect that Yoruba vernacular architecture is dependent on culture.

\section{Challenges of Yoruba Vernacular Architecture.}

The Yoruba region lying in the western part of Nigeria is believed to be the cradle of western education and civilization in the country. The influence of westernization which saw to a drastic change in their religion, orientation and life styles also has a great influence on their architecture owing to the fact that westernization saw the introduction of foreign building materials and technology which are adjudged to be more durable than the local materials and hence impacted their taste and preference (Jolaoso et al, 2017).

\subsection{Introduction of modern technologies and foreign materials}

All vernacular architecture in the world experienced changes due to limitations and challenges in construction methods and materials. Continuous challenges call for continuous discoveries of the better use of materials and construction methods. This however informed the use of modern materials and methods of construction across the continents of the world.

Yoruba vernacular architecture has experienced some changes in appearance right from the colonial era. This is due to the introduction and adoption of foreign materials such as cement, corrugated roofing sheet among others, styles of building and construction techniques ( Sonaiya and Dincyurek, 2009).

\subsection{Durability of foreign materials}

It is perceived that certain foreign materials such as galvanized zinc, cement lasts more than local thatch that is locally used as roofing materials in traditional building practice. As such, the replacement of thatch roof with galvanized iron roofing sheet becomes a new traditional building practice contrary to thatch which was formerly in use (Adedokun, 2013).

\subsection{Taste and Preference}

Agboola et al (2014) in their findings posited that preference for modern materials among the Yorubas especially in terms of wall rendering and finishing to display their level of civilization, achieve aesthetics and display their wealth and affluence has also caused a great challenge to the sustenance of Yoruba vernacular architecture.

\section{4. Local materials and construction methods of Yoruba vernacular architecture- an overview of their strengths and weaknesses.}

4.1 Local materials

Among several others, basic materials considered for local building among the Yoruba folks are laterite (clay), timber, bamboo, thatch and animal dung. Emphasis has however been laid on the strength and weaknesses of these materials and hence, the need to merge them with modern technology (Opaluwa, Obi and Osasona, 2012).

4.1.1 Laterite (clay)

Laterite (clay) is the most common wall materials in traditional Yoruba culture due to its high level of plasticity when mixed with water (Adekunle et al., 2008). This guarantees a high level of adhesion when used. Its dried surface also produces workable surface that can be used for aesthetic finishes such as artistic decorations. It also produces a beautiful outlook even without any further surface finishes owning to its natural colour (reddish brown). It can also be easily combined with other building materials such as timber. However, laterite has a poor tensile strength and a poor load bearing capacity and cannot support its own weight when wet. Apart from this, surface 
of laterite walls easily get abraded and washed away when subjected to high rainfall (Osasona, 2005).

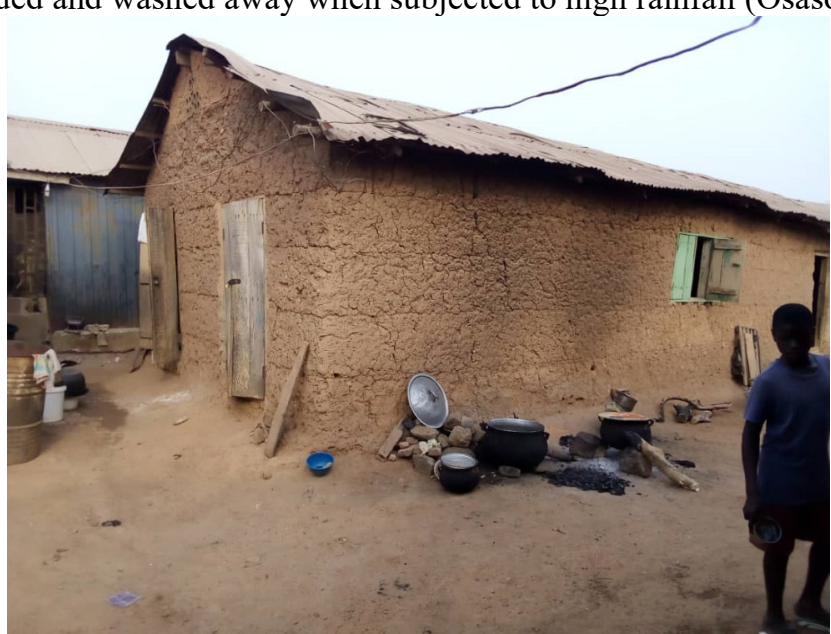

Plate 1: Reddish brown surface of a wall constructed with laterite: Authors Field work, 2019

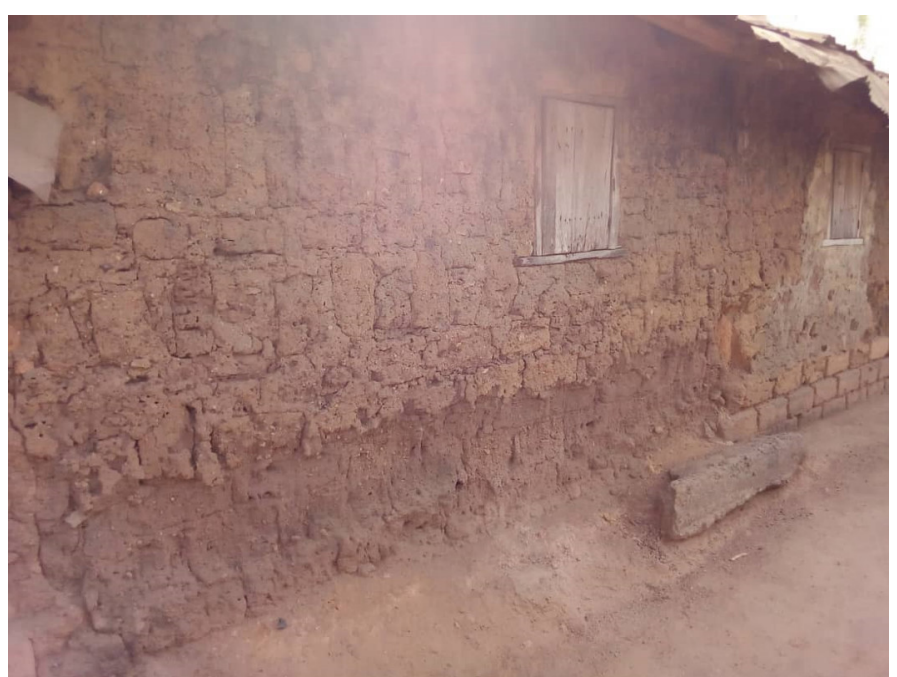

Plate 2: Abraded surface of a wall constructed with laterite:

Authors Field work, 2019

\subsubsection{Timber and Bamboo}

Timber and bamboo are important materials of Yoruba vernacular architecture due their tensile strength. The tensile strength the duo possess has encouraged the use of wattle and daub wall construction in Yoruba folk architecture. They are also used in and outside building as load bearing elements. Timber and bamboo are characterized by workable surfaces that can be used for decorative purposes such as caryatids and totem poles. Apart from this, they are used for roof construction and perimeter fencing (Adekunle et al., 2008). However, lack of preservative knowledge by the Yoruba folks have seen timber and bamboo being attacked and destroyed by insects, termites and incessant rainfall especially when used as building fabrics or perimeter fencing.

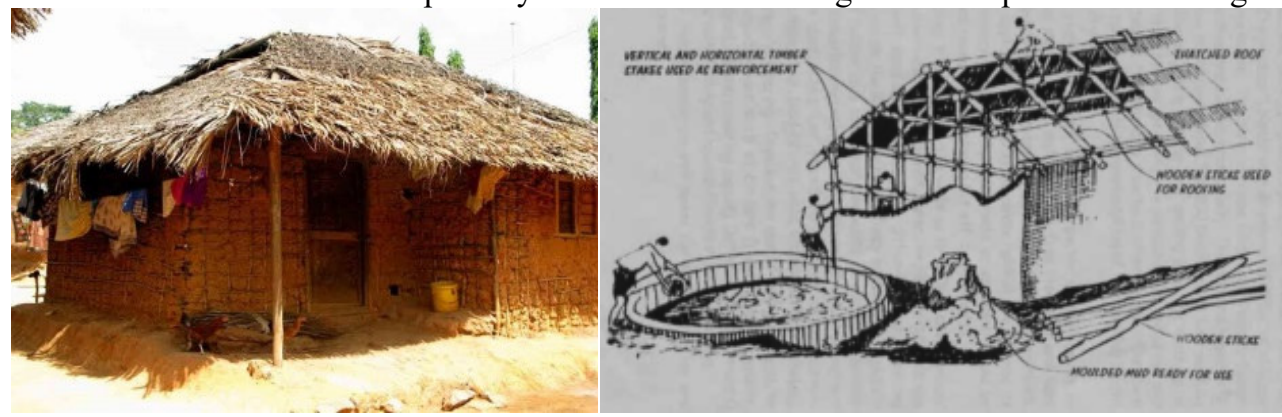

Plates 3\& 4: Bamboo and timber used as structural support in laterite wall construction. Source: Adekunle et al., 2008. 


\subsubsection{Thatch (Palm fronds)}

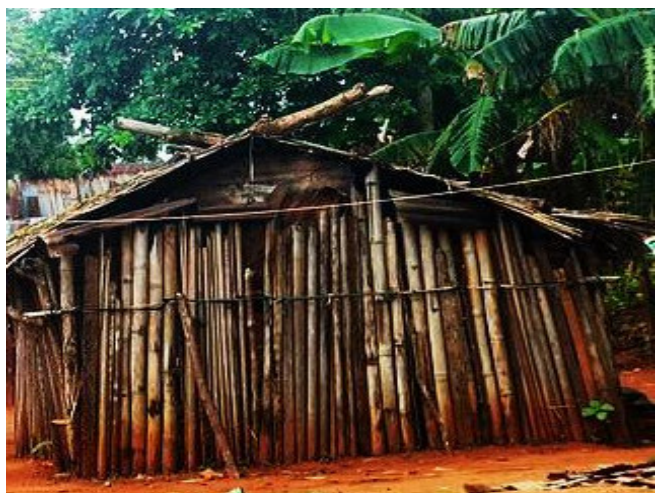

Plate 5: Effect of incessant rainfall on bamboo wall.

Source: Adekunle et al., 2008.

Thatch (Palm fronds) is considered important building material of the Yoruba vernacular architecture due to their durability, light weight and ease of workability. Thatch is used basically for roof covering among the Yoruba folks owning to its water resistant and natural thermal insulation properties. However, thatch is said to have a great tendency of rotting and is prone to discoloration (Osasone, 2005).

4.1.4 Animal dung and wastes

Animal dung and wastes are mostly used for wall and floor finishes among the Yoruba folks. However, Adekunle et al. (2008) noted that the Yoruba vernacular architecture suffered setbacks owning to the fragile nature of their building materials and simplicity of working tool.

\subsection{Local methods of construction}

The concept of master builder in Yoruba folk architecture does not exist. The cultural belief among Yoruba folks about building construction is that it is a community affair whereby the builders are the associates of the intending building owner this however means that the building owner only expend a small amount of money basically on feeding, from the inception to completion (Osasona,2005).Materials combination for construction such as reinforcing the earth wall with timber and bamboo, tying of timbers together, swish puddling (treading on wet earth with the feet for plastic consistency) among others require little energy by the builders to achieve their goal.(Adekunle et al.,2008 and osasona,2005)Roof design is made with thatch and palm fronds .These materials are sound proof and as such reduce environmental hazard such as noise pollution. This method of construction however ensures a low cost of production and simple method of construction because labour and materials are readily available and there is neither ambiguity nor technicality in the construction technique.

However, absence of maintenance culture and lack of technological advancement to meet up with the new demand of people are major challenges Yoruba vernacular architecture is faced with and this has caused a drastic shift to foreign materials and methods.

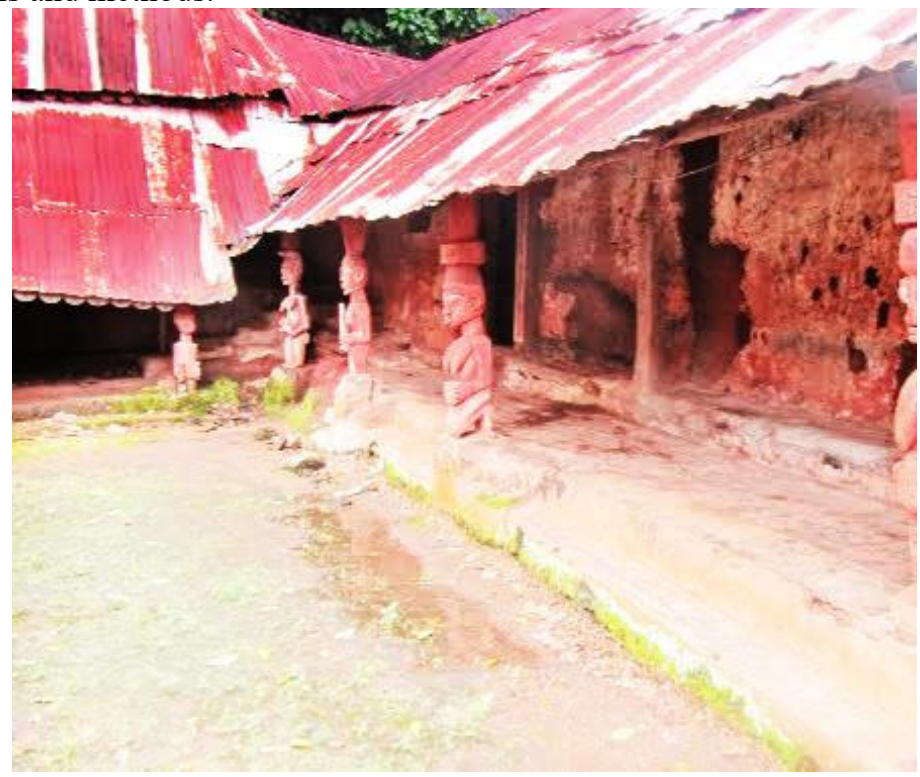

Plate 6: Abandoned Yoruba vernacular architecture at Idanre town, Ondo state, Nigeria. Source: The Sun news, 2018 


\subsection{Modern materials and Technology}

Modern technologies have been improving for number of reasons, amongst which is the review of the existing built forms and an attempt to improve the status of the built environment. As a result, there is no limit to the production of building materials across the globe. The laudable solutions offered by modern construction materials and techniques to long time quest and yearnings of the people have caused the drastic shift from the old materials and methods to the recent modern ones and this has posed a serious threat on the rich cultural heritage and vernacular architecture of most African communities. Some of the opportunities provided by these modern materials and methods include

1. Combination of materials with high compressive and tensile strength for structurally stable buildings. This could be seen in the combination of concrete and steel reinforcements for columns and slab constructions.

2. Use of roof overhangs to prevent the effect of weather such as incessant rainfall on building walls.

3. Use of concrete floor to prevent the activities of termite.

4. Use of water repellant finishes such as ceramics floor and wall tiles.

5. Erecting buildings that can go on several numbers of floors with reliable structural support.

However, the very high cost of production, high environmental hazards coupled with their disregard for climatic suitability has made modern building materials unsuitable for use (Adekunle et al., 2008). Apart from this, modern building materials have a total disregard for the rich vernacular inheritance of the African culture and hence impose a continuous treat on the vernacular buildings of the Yoruba folks and Africans at large

\subsection{Synthesizing local materials and modern construction methods}

Jolaoso et al. (2017) posited that a completely traditional society which would exclusively reflect vernacular architecture cannot be achieved again in this new era considering the technological advancement and the demands of the society. However, it is practicable to synthesize the knowledge of the traditions with modern technological developments in terms of application of modern construction methods and traditional building materials in order to reminiscence the old in the new era in a complimentary and appealing way. This is the only sure way by which Yoruba vernacular architecture can be revived and maintained. To achieve this, the weakness of the traditional building materials is expected to be complimented by the strength of the modern construction methods. Further illustrations are given below:

1. Modern technologies could be adopted in dry walls construction with the use of local materials such as bamboo as the structural elements. This would reduce the cost of production as it is not as bamboo is not as expensive as concrete and steel reinforcements.

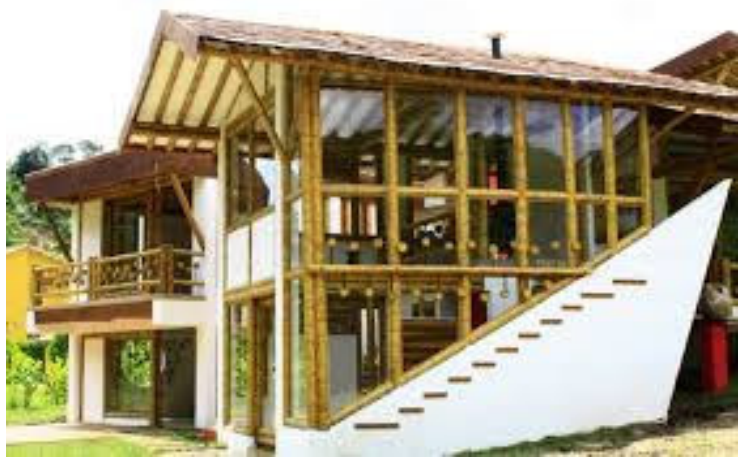

Plate 7: Bamboo as fabric and structural support for building.

Source: MT Bamboo Plywood, 2020

Replacement of structural members with bamboo would avoid the problem that comes with modern construction methods such as noise pollution that would have resulted from cutting and welding of steel frame structures. The cost of construction and workmanship would also be greatly reduced. Treatments such as painting and spraying with insect repellent chemicals would ensure longer life span of the bamboo to be used. The building would also carry a symbol of Yoruba vernacular architecture. 


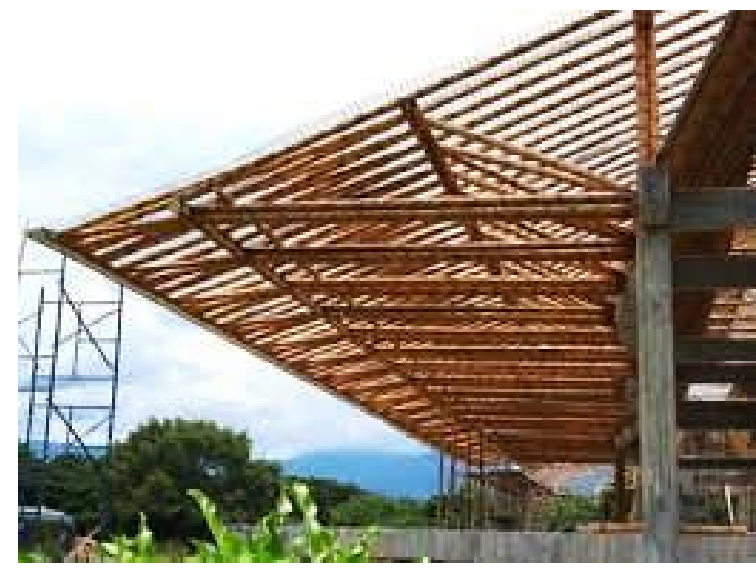

Plate 8: Bamboo as roof structural members

Source: Jason, 2012

Apart from these, the use of bamboo for wide overhangs due to its high tensile strength can be used to protect abrasion on laterite or mud wall when used as building walls. It can also be used as roof members with a careful use of modern construction methods.

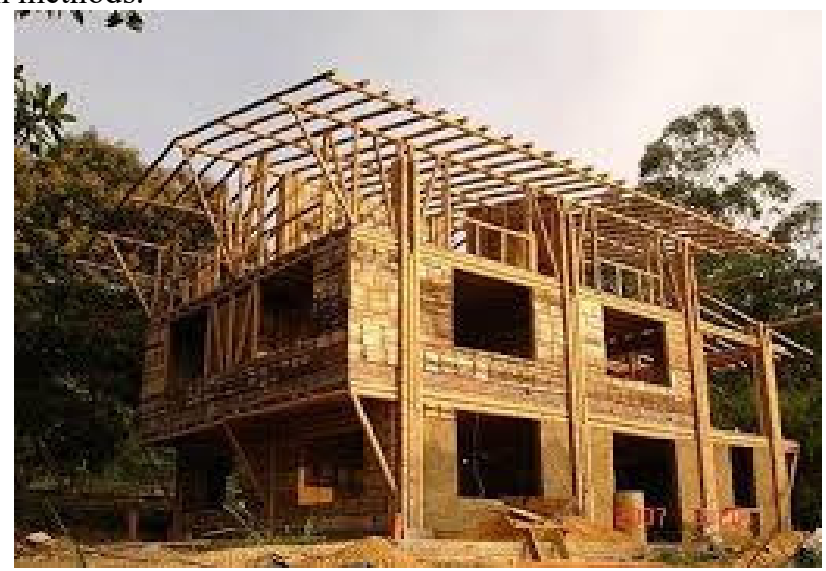

Plate 9: Bamboo as roof structural members and column supports

Source: Jason F., 2012

2. Just like bamboo, well seasoned and preserved timber with the use of modern technology could minimize greatly rot and termite attacks noticed in their use in vernacular buildings. The use of well seasoned timber and its products such as plywood, particle boards etc for interior partitions, floor covering and roof members would greatly reduce cost of construction as they are readily available.

3. Modern construction techniques and methods have also greatly influenced the use of thatch roof (palm fronds). It has not only seen its use in a relatively large span but has also uplifted the aesthetic view it gives to buildings.

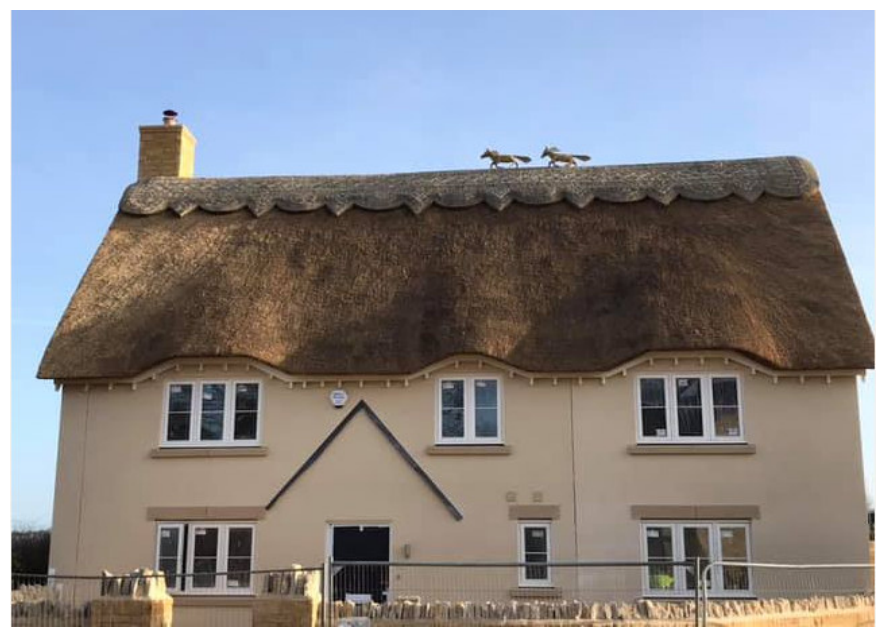

Plate 10: Thatch roof used as roof covering.

Source: Heart of England Thatcher, 2020 
4. Compressed earth block is seen as one of the ways local materials have been improved. This according to Opaluwa et al., (2012) is the process of mixing natural laterite with certain percentage of cement or lime to produce compressed earth blocks. The addition of little cement would take care of the weakness of laterite. It was however been noted that building made with compressed earth block tends to have the strength to carry impending loads by the roof than the wattle and daub methods used by the vernacular system.

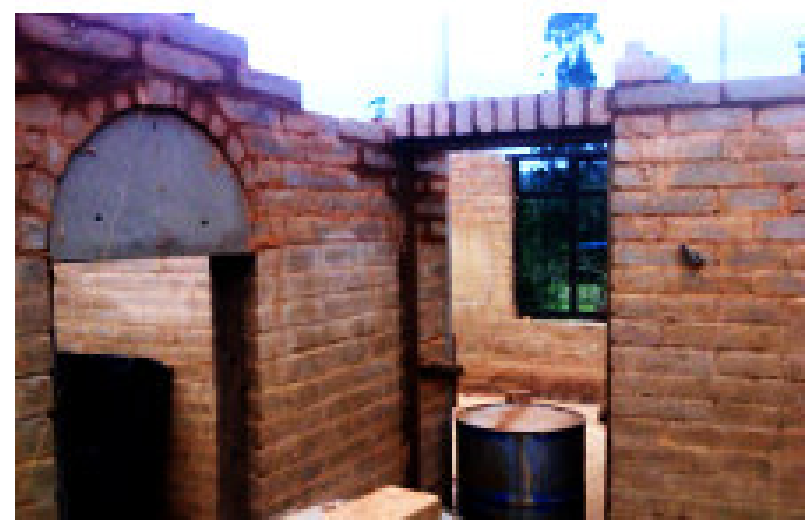

Plate 11: Compressed earth blocks for wall made from the mixture of cement and laterite. Source: Opaluwa et al., 2012.

\section{Conclusion and Recommendations}

This paper has revealed that the drastic shift from vernacular buildings to modern ones by the Yoruba folks was majorly because of the wide gap between foreign and local building materials and techniques of construction which saw the modern materials and techniques of construction fulfilling their recent demands for civilization, modernization, display of wealth and affluence and new religious believes. However, as spontaneous as the foreign materials are, the high cost of procurement and their disregard for the climatic requirements of the Yoruba region imposes serious challenge. This is also in line with the submission of Obot, (2007).

The study has however established that careful merger of both the traditional materials and foreign construction methods could be an important tool for reviving Yoruba vernacular architecture and delimit the negative effects of the modern materials. This innovation involves combining local materials and modern construction methods for efficient building production. However, this new innovation is expected to produce buildings that satisfy the taste for modernity among Yoruba people without jettisoning the status of their vernacular architecture.

The revival and enhancement of Yoruba vernacular architecture through the careful blending of local materials and modern construction methods would be greatly achieved with the following measures;

1. Building design of this style should be adopted by the architects and engineers in the Yoruba region and Africa in general as their new design and construction styles.

2 . Renovation of notable and abandoned ancient buildings across various cities and towns of Yoruba land should be done with this method.

3. Formulation of policy regarding the implementation of these methods across various public and private buildings in Yoruba land should be ensured by the government.

4. This style of building should be adopted by the government and other private sectors in areas of real estate business to produce edifice that will be affordable for the masses and which would also symbolize their cultural origin.

From the foregoing, it can be clearly stated that the thin line identified between the problems and solutions of Yoruba vernacular architecture in reference to modern construction methods can be bridged by the aforementioned recommendations.

\section{Conflict of interests}

The authors have not declared any conflict of interests.

\section{References}

Adedokun, A. (2014), "Incorporating Traditional Architecture into Modern Architecture: Case Study of Yoruba Traditional Architecture". British Journal of Humanities and Social Sciences. 1 (2) , 30-45.

Adekunle, T.O. \& Odeyale, T.O. (2008), "Innovative and sustainable local materials in traditional African Architecture", London:Taylor and Francis Group.

Agboola, O.P. \& Zango, M.S. (2014), "Development of traditional architecture in Nigeria: A case study of Hausa house form", Journal of African Society Culture and Tradition 1 (1) 61-74. 
Heart of England Thatchers. (2020), "Why get a Thatch Roof”, https://www.heartofenglandthatchers.com/havinga-thatched-roof.

Jason, F. (2012), “Team Investigates Potential of Bamboo for Home Construction”, Retrieved from www.theengineer.co.uk/team-investigates-potential-of-bamboo-for-home-construction.

Jolaoso, B.A. \& Bello, O. A. (2017), "Character-Extinction of Yoruba Architecture: An Overview of Facades of

Residential Buildings in South-Western, Nigeria", Journal of Emerging Trends in Educational Research and Policy Studies (JETERAPS) 8(3): 143-150.

MT Bamboo Plywood, (2020), "World Bamboo Buildings", https://plybamboo.wixsite.com/vietnam/worldbamboo-buildings

Obot, I.D. (2007), "Sustainability in African architecture: problems and prospects", Conference Paper presented on African Architecture Today at Kwame Nkrumah University of Science and Technology, Kumasi, Ghana.

Opalunwa, E., Obi, P. \& Osasona, O.C. (2012), "Sustainability in traditional African architecture: A springboard for sustainable urban cities", Journal of Architecture and Urbanism in the Global south.

Osasona, C. (2005), "Ornamentation in Yoruba folk Architecture ", Ibadan: Book Builder Edition Africa

Rapoport, A. (2005), "Culture, architecture and design”, Chicago: Locke science

Sonaiya, O.A. \& Dincyurek, O. (2009), "Tradition and Modernism in Yoruba architecture: Bridging the Chasm”, Open House International 34 (74-81)

The Sun News. (2018), "Idanre Hills: Where Old World Wonders are Preserved at the Hilly Peaks Inhabited by a Warring god”, https://www.sunnewsonline.com/idanre-hills-old-world-inhabited

Muritala Muideen Olaniyi. (B.Sc, M.ed) Studied Architecture at the Obafemi Awolowo University, Ile-Ife, Osun State. He bagged his Masters' degree at the University of Lagos, Lagos state, Nigeria.

He currently lectures in the Department of Architectural Technology, Osun State Polytechnic, Iree, Osun state. His research focus is on Housing and Traditional Architecture.

Adebisi Ilelabayo, Ismail. (B.Tech, M.tech) Studied Architecture at the Federal University of Technology Akure. He bagged his M.Tech degree in the same institution and he is currently licensed to Practice Architecture in Nigeria.

He currently lectures in the Department of Architecture, Ladoke Akintola University of Technology, Ogbomoso, Nigeria. His research focus is on Bioclimatic Architecture, Architectural climatology and Sustainable designs.

Olatinwo Fatai Aderinola. (B.Sc, M.Sc) Studied Architecture at the Amadu Bello University, Zaria, Nigeria where he bagged his B.Sc and M.Sc degrees.

He currently lectures in the Department of Architectural Technology, Federal Polytechnic, Offa, Kwara state. He is also the Director of Physical planning and projects unit of the same Institution. His research focus is on Housing and Traditional Architecture. 